\title{
Reform and Practice of Hydraulics and Pneumatics Course
}

\author{
Meng Qingyun \\ Dalian Vocational and Technical College, Liaoning Dalian 116037
}

Keywords: Enterprise training, hydraulics and pneumatics, course reform

\begin{abstract}
Enterprise training is the main way of improving the quality of employees. training course reform directly determine the effect of training. In the School-enterprise cooperation, the author reform the hydraulic and pneumatic course based on the requirements of the enterprise. At the same time, the practice process and effect was summarized.
\end{abstract}

\section{Introduction}

With the rapid development of economy, the competition between enterprises are increasingly fierce. More and more enterprises realize that if you want to in the fierce competition, is the most effective way to improve staff quality. Employee's quality is the enterprise key factors to realize the strategic target, the enterprise only strengthen staff training, strengthen knowledge skills updated to keep pace with the development of new technology, only the overall level of the staff through training to improve. The enterprise training can be effective implementation, in the final analysis depends on the training teaching. Successful training teaching to improve the quality of training, improve enterprise efficiency is of great importance.

Enterprise staff training teaching, there are two categories, although these two approaches also played a role in objectively, but are not the best effect of training. One is relying on the enterprise internal training teaching, shortcomings embodied in the depth of knowledge is insufficient, can't form a system, standardize the knowledge system; Another kind is sent staff to the corresponding training colleges and universities, but training teaching content from the production practice, technical application ability and practice ability is poor. Therefore, through the cooperation between colleges to reform practical teaching to complete the training gradually become the best choice for modern enterprise training.

Based on the actual production needs, dalian Goodyear tire co., LTD university-enterprise cooperation with our university in 2009, sets the enterprise's training base in campus, mainly undertakes professional skill training work, reliability technician in theory and in practice to lay a solid foundation for the employees, improve the comprehensive skill level. University-enterprise cooperation with Goodyear in the university staff training process, the reliability of technician for the enterprise to carry on the multiphase class (now completed 12, 20 people/period) of training, the author mainly be responsible for the training part, hydraulic and pneumatic in the training process, abandon the disadvantages of traditional teaching methods, adopted the new training method of combination between colleges, according to enterprise actual production of hydraulic and pneumatic training teaching reform and practice. Satisfactory training results have been achieved. 


\section{A more targeted, training content, a combination of theory and practice}

The reliability of the training technicians from enterprises, most of the technical secondary school or above college degree, according to the students' cultural foundation, practical training content must be combined with the training object and business requirements to reform. Based on the actual situation of training, training in the following aspects in the reform of the teaching.

\subsection{Part of the theory of hydraulic and pneumatic training teaching reform}

Combination with the engineering practice teaching theory of hydraulic and pneumatic content properly cut. For fluid mechanics parts (such as the flow of the fluid, Bernoulli equation, etc.), the body structure analysis, the structure design of the hydraulic cylinder, mailboxes, hydraulic system design and so on the content of the theory too because for reliability technician, does not belong to must master the professional knowledge, should be deleted.

For some is not consistent with the engineering practice link, be modified appropriately. Engineering, for example, use $\mathrm{kg}$ force as pressure unit, and the Goodyear enterprise mainly adopts the European and American elements, therefore in the interpretation of the pressure unit, not limited to international unit, need to take all kinds of pressure unit is commonly used to explain and differences.

For hydraulic and pneumatic components, conventional teaching contents, the types of element is introduced, with the rapid development of hydraulic and pneumatic technology, the renewal speed of components with each passing day, according to the enterprise, the application of the components, should be combined with manufacturers to provide product manual operation and maintenance of the new element is introduced and explained.

In the analysis of typical hydraulic and pneumatic systems, requires the introduction of enterprise in the form of loose materials engineering drawings, hydraulic and pneumatic study in element on the basis of not only master the analysis method of hydraulic and pneumatic system, and to have a clear understanding of the enterprise production equipment, able to skillfully use the relevant components.

In addition to the above points, in the teaching should also strengthen the proportional valve, plate valves, superposition valve and cartridge valve new body, more combination with the engineering practice to analyze its characteristics and key points for installation. Content selection principle is: practice supplemented, theory, emphasize unity, real one.

\subsection{The practical operation of hydraulic and pneumatic training teaching part of the reform}

University-enterprise cooperation to make our school training center has the domestic first-class hydraulic and pneumatic hydraulic tong, air training rooms, training rooms, complete auxiliary teaching equipment industry well-known enterprises such as (Festo, Rexroth, SMC hydraulic and pneumatic components, etc.). To carry out the practice teaching of hydraulic and pneumatic laid a solid material foundation and powerful guarantee.

It should be pointed out that, in the teaching practice before operation, all to attend training personnel should consult factory production procedure to join the security education part, through safety education, not only can ensure the personal safety and equipment safety in the process of students in the experiment. Also can make the students into the role as soon as possible, into the actual production, have the ability to meet the requirements for factory work. This is always in the training needs through a corporate culture, namely: safety awareness.

Past practice, hydraulic and pneumatic only for basic elements and basic circuit system to carry on the simple experiment operating practice, actual project belongs to the verification. No enterprise demand oriented, characterized by high requirement to the theoretical knowledge, while low practical ability. It is difficult to make students adapt to work immediately after induction. 
Therefore, in view of the enterprise actual requirements and carry out the experiment project has become the primary task of teaching reform.

In training, in order to strengthen the students practical ability, make its faster familiar with the factory equipment, according to the production equipment in the rubber enterprise vulcanizing machine, vulcanizing machine developed hydraulic valve group simulation experiment and vulcanization machine pneumatic valve test bench. Directly using the factory system in practice are the drawings of the local loop circuit form and as a guide for operation, the system is reformed and simplified, so that the handling, training and practice examination in the end. Such training devices in the training effect is remarkable, maximum exercise the students' practical ability, greatly improving the students' interest in learning.

Training guide take the form of sheet, under the basic training curriculum according to the actual need with the different content, and enrich the improvement according to production requirement, and increase the new case. Training content closely linked with the enterprise of equipment system, the timely access to the latest technology development of information and industry leading technical equipment, implementation technology to keep pace with The Times, updated in real time.

Also took the training idea of "introduction to, go out", in addition to the invitation from a line of engineering and technical personnel of enterprises, engineers to participate in the interpretation of some internal professional cross strong equipment and emerging technologies, also according to the needs of training at the appropriate time to send students to enterprise field learning practice.

\section{The implementation and assessment of teaching reform}

On the teaching method, hydraulic and pneumatic components of teaching mainly USES the direct-viewing teaching method; Hydraulic principle, hydraulic system mainly adopts the teaching method of teaching. To practice while speaking, the teaching methods of combining theory with practice. And make full use of modern education technology, to some difficult to express clearly movement process of using $3 \mathrm{~d}$ animation and video illustration.

In teaching organization, mainly adopts team teaching method, usually in groups of five, all kinds of practical operation training, the teaching organization way conducive to the rational use of teaching resources and maximize provide practical opportunities for students. At the same time improve the students' ability of group cooperation ability and organization and coordination.

Change the traditional way of teaching evaluation at the same time, in addition to take the request for the test, also by vulcanizing machine of hydraulic and pneumatic analog device form and operation to test students' practical ability (need a four test), and refer to the assessment of enterprise standards, respectively, for security, system form, demonstration effect, system analysis and supposed the project such as $5 \mathrm{~s}$, then combining the theory of ordinary performance and test the final evaluation of undergraduate course grades.

\section{Teaching evaluation and continuous improvement}

\subsection{Students feedback after training}

Return to students after the training, the enterprise work after a period of time, according to their own learning experience and practical application situation, proposed the teaching improvement feedback form (teaching), for teaching content suggestion summary by the enterprise after the transfer of training teachers, training teachers, discretion to determine whether to adjust the next class training. In the process to continuously review and feedback, ascension. Help to improve training effect and the quality of training. 


\subsection{The enterprise according to the training of the enterprise after performance feedlback}

First, the technical personnel by the enterprise according to the actual demand to determine the entry exam content, carries on the inspection before the students take part in training, achievements recorded, certificate is still using the same paper, comparing the gap between before and after the training, technical staff by the enterprise summary analysis, feedback to the training of teachers, in view of the weak link, for the next class training properly adjusted.

Second, each staff to attend training in full after three months, the competent department technology to the feedback of the training center, after training for the employee performance of deficiency in detail, the training of teachers by aiming at the shortcomings of the relevant teaching is improved accordingly.

\subsection{Teachers and enterprises to strengthen contact, obtain first-hand information feedback}

Training teachers every year in the form of one's credentials the exercise field work, such as short-term into the enterprise, to deepen understanding of the training posts, obtain the most direct first-hand information, for continued ascension to improve the teaching.

After the reform of hydraulic and pneumatic training teaching is well in the concrete implementation process. Since 2010, has now completed twelve periods before and after reliability technician training training, it turned out that training students interest in learning, teaching, teaching effect is good, because the hydraulic and pneumatic training combined with enterprise engineering practice closely after teaching reform, training students to have the technical personnel's professional quality and skills required to enterprise, to more quickly familiar with the actual work environment, put into production as soon as possible. Create a higher economic value, is fully recognized by the cooperative enterprise. This is based on the requirements of the enterprise training model will be reflected more in the future teaching advantages, is bound to become a professional colleges and universities teaching training and the best model.

\section{References}

[1] Hanyuan Gao etc. Modern enterprise training mode and training mechanism research [J]. Vocational and technical education, $2001(25): 39-41$

[2] Chuanyong Le, etc. Based on the development of enterprise training curriculum under the adult learning characteristics analysis [J]. China's adult education, 2007 (31) : 17-19

[3] Shenggang Ma etc. Curriculum teaching reform exploration of the hydraulic and pneumatic transmission [J]. Hydraulics and pneumatics, 2008 (12) : 12-14.

[4] Guangzheng Jia, etc. "hydraulic and pneumatic" experimental teaching mode of study [J]. Machine tool with hydraulic, 2007, (2) : 151-152 